\title{
亞既蒴殼の乳牛の泌乳量及び 脂肪量に及泀す影響
}

\section{井口賢三・三田村健太郎・种谷俊雄}

（北海道帝國大學農學部）

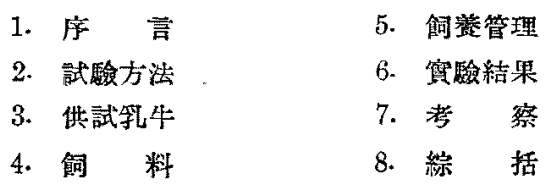

序言

亞麻は繊維用工藝作物として最も重要なるのの一つであつて，本邦で自給 し得る唯一の紡績原料である。その製品たる亞梳織維は軍需品として缺く可

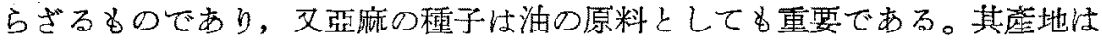
我國では北海道に限られて居る。北海道に亞麻栽培が發展したのは明治 22 年以來のことで，それか昭和 8 年にはその作付反別が 13174.3 町步に荹して 居るが今日迄一つの困難に惱委されて來を。

それは亞䟽が尰作不能なことである。連作不能の原因将第一に立枯病，第 二に地力の消耗のために收穫物の草文と收量の減少である。この中，立枯病 の被害は甚大で賞事者が此の缘防に最も苦心を拂つて居る所である。立枯病 は Fusarium Lini BOLLEY の笴生に依つて起る事は兂に知られた所であり， 今日迄の研究結果に依れば Fusarium 菌は亞㓷收穫後畑周に殘された蕉根そ の他の有機物中に越年すること數年に及び，少くと草7-8 年を經過しなけ

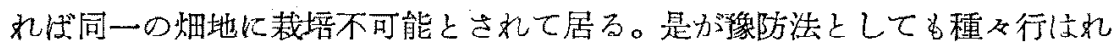

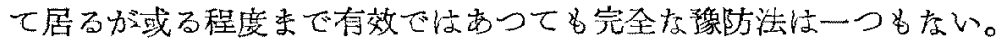

從來一般に推賞されたこの防護法として被害蕉葉は勿諭, 無被害のものの

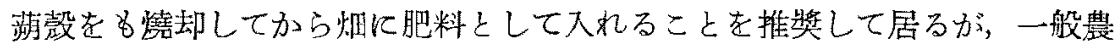

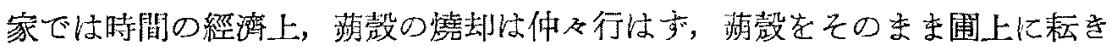


込むものが多いのでする。この橴存有樣では立植病の豫防の萬全を期し難い

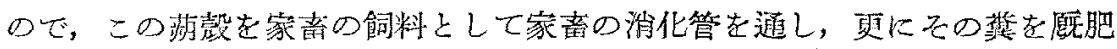
上して府熟されをならば FuSarium 菌を撲隇し得るのではねいかとも考へら

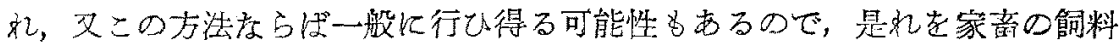

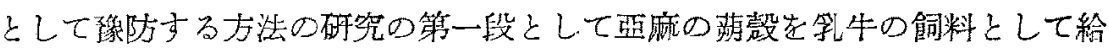
與した場合如何存る影響を乳牛に與人るか子實驗研究した次符である。

\section{試 驗 方 法}

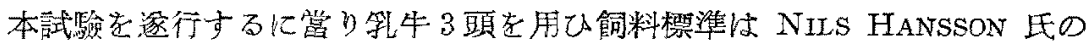

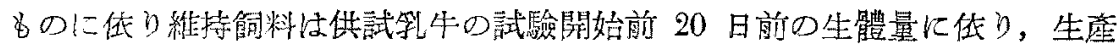
铝料は牛乳の生黨量に應じて算出した。

全試驗期間を分ちて 3 試驗期とし，1 試驗期をそれぞれ 15 日とし，更に

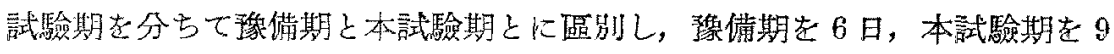
日とし，镌備期は解試驗期の影響があるので本試驗期の結果に就てのみ檢討 Lた。

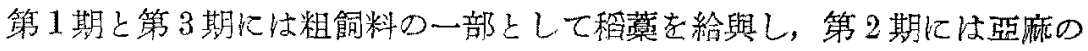

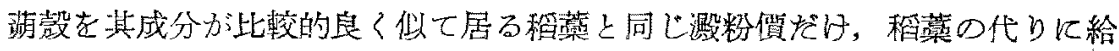
其した。斯樣にして此の2つの飼料为浮量及び牛乳中の脂肪量仁如何に影響

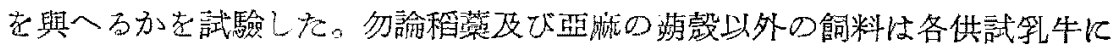
就き，全試驗中少し为變へなかつた。

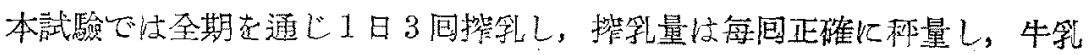
の Sample は搾乳每に㩲乳量に比例してとり集めを Composit Sample 用ひ，每日之に就て $\mathrm{BABCOCK}$ 氏法で脂肪率を求的た。

\section{供試 孚 牛}


で 1 日約 $15 \mathrm{~kg}$ ○牛乳を生産するもの3頚を選ん方。此等の牛の履歷に就て 㦛げると次の樣である。師ら殆ど似た條件のるののみである。 


\begin{tabular}{|c|c|c|c|c|c|c|c|c|c|c|}
\hline 生童番觊 & \multicolumn{3}{|c|}{ 生年月日 } & \multicolumn{3}{|c|}{ 鼠近の分婏日 } & 產 次 & \multicolumn{3}{|c|}{ 最後の種付日 } \\
\hline 346 & $\begin{array}{l}\text { 昭和脌 } \\
7\end{array}$ & $\begin{array}{r}\text { 早 } \\
11 .\end{array}$ & $\begin{array}{l}\text { 早 } \\
5 .\end{array}$ & $\begin{array}{l}\text { 昭和年 } \\
10 .\end{array}$ & $\begin{array}{l}\text { 月 } \\
8\end{array}$ & $\begin{array}{l}\text { 早 } \\
7 .\end{array}$ & 1. & $\begin{array}{c}\text { 昭和年 } \\
10 .\end{array}$ & 12. & $\begin{array}{r}\text { 日 } \\
31 .\end{array}$ \\
\hline 353 & 8. & 3. & 3. & 10. & 8. & 25 . & 1. & 11. & 2 & 17. \\
\hline 354 & 8. & 4. & 24. & 10. & 8 & 20. & 1. & 10 & 12. & 7. \\
\hline
\end{tabular}

飼料

本試驗に於て使用した飼料は次表の樣な成分を有するもので，何れも本試 驗の䉆めに分析した。

\begin{tabular}{|c|c|c|c|c|c|c|c|c|}
\hline & 水 分 & 粗蛋白筫 & 粗脂肪 &  & 粗縰組 & 粗灰分 & \begin{tabular}{|l|} 
可滔化 \\
蛋白質
\end{tabular} & 湻粉㵋 \\
\hline 藻 & 22.68 & .00 & 1 & 31.60 & 28 & .00 & 1.98 & 12.28 \\
\hline 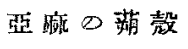 & 16.62 & 5.56 & 5.32 & 27.10 & 37.20 & 20 & 1.61 & 11.67 \\
\hline 数 & 12.45 & $13-91$ & 5.35 & 53.95 & 9.29 & .05 & 9.88 & 47.50 \\
\hline 大豆 粕 & 12.60 & 33.81 & 1.95 & 39.35 & 7.21 & 8 & 29.75 & 70.54 \\
\hline 燕 & 12.15 & 8.58 & $f$ & 59.56 & 12.04 & 0 & 6.09 & 56.39 \\
\hline エンシレーヂ & 82.82 & $1.4 \mathrm{I}$ & 0.77 & 8.52 & 5.21 & $\mathbb{1} .27$ & 0.36 & 7.60 \\
\hline
\end{tabular}

HANSSON 氏に依ると生體量 $500 \mathrm{~kg}$ に罣し澌粉價 $2.4 \mathrm{~kg}$ ，可消化蛋白質

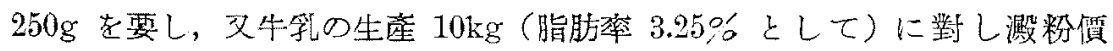
$2.333 \mathrm{~kg}$, 可消化の蛋白算 $460 \mathrm{~g}$ を要するのである。故に試驗開始前 20 日前



\begin{tabular}{|c|c|c|c|c|c|c|}
\hline 生率番虎 & 生體量 & 平均乳复 & 榮 筌 分 & $\begin{array}{r}\text { 維持验料 } \\
\mathrm{g}\end{array}$ & $\begin{array}{r}\text { 生茛鸽料 } \\
g\end{array}$ & $\begin{array}{r}\text { 部 } \\
\mathrm{g}\end{array}$ \\
\hline \multirow{2}{*}{346} & \multirow{2}{*}{$479 \mathrm{~kg}$} & \multirow{2}{*}{$15 \mathrm{~kg}$} & 厡 粉 價 & 2300 & 3500 & 5800 \\
\hline & & & 可消化盆白签 & 240 & 690 & 930 \\
\hline \multirow{2}{*}{353} & \multirow{2}{*}{$574 \mathrm{~kg}$} & \multirow{2}{*}{$15 \mathrm{~kg}$} & 洬 粉 琵 & 2760 & 3500 & 6260 \\
\hline & & & 可消化蛋白質 & 287 & 690 & 977 \\
\hline \multirow{2}{*}{354} & \multirow{2}{*}{$570 \mathrm{~kg}$} & \multirow{2}{*}{$15 \mathrm{~kg}$} & 滶 粉 儥 & 2740 & 3500 & 6240 \\
\hline & & & 的消化蛋白琶 & 285 & 690 & 975 \\
\hline
\end{tabular}


次に濃量伺料の混合割合忙次の样である。

\begin{tabular}{|c|c|c|c|c|c|c|}
\hline 䬨 & 料 & 名 & 重 & 量 & 澱粉黛 (g) & 可消化蚠白筫 \\
\hline 数 & & & \multicolumn{2}{|c|}{$2.4 \mathrm{~kg}$} & 1140 & 237 \\
\hline 火 & 효 & 粗 & \multicolumn{2}{|c|}{1.2} & 816 & 357 \\
\hline 燕 & & 麥 & \multicolumn{2}{|c|}{3.0} & 1692 & 183 \\
\hline 合 & & 部 & \multicolumn{2}{|c|}{$6.61 \mathrm{~kg}$} & 3678 & 777 \\
\hline \multicolumn{3}{|c|}{$\begin{array}{l}\text { 混合物 } 7 \mathrm{~kg} \\
\mathrm{~K} \supset \text { 己 }\end{array}$} & \multicolumn{2}{|c|}{7.0} & 3899 & 826 \\
\hline
\end{tabular}

ツ上の他に濃厚解料の $1.5 \%$ 宛の骨粉及び食譬

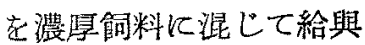
した。試驗期中に倛試牛 に給與した餇料の量は次 の表の樣である。

第一斯及第三期闹料給與量

\begin{tabular}{|c|c|c|c|c|c|}
\hline 生应舀號 & & 稻缲 & エンシレーチ & 混合鲇料 & 合計 \\
\hline \multirow{3}{*}{346} & 重 䔬 $(\mathrm{kg})$ & 4.76 & 20.00 & 6.60 & \\
\hline & 澱 粉 留 $(\mathrm{kg})$ & 0.585 & 1.520 & 3.678 & 5.78 \\
\hline & 可消化蛋白澌 $(\mathrm{g})$ & 94 & 72 & 777 & 943 \\
\hline \multirow{3}{*}{353} & 重 量 $(\mathrm{kg})$ & 4.28 & 24.40 & 7.00 & \\
\hline & 瑖 粉 偵 $(\mathrm{kg})$ & 0.526 & 1.854 & 3.899 & 6.28 \\
\hline & 可消化蛋白县 $(\mathrm{g})$ & 85 & 88 & 826 & 999 \\
\hline \multirow{3}{*}{354} & 重 量 $(\mathrm{kg})$ & 4.09 & 24.40 & 7.00 & \\
\hline & 澱 粉 䨘 (kg) & 0.502 & 1.854 & 3.890 & 6.26 \\
\hline & 的消化蛋白質 $(\mathrm{g})$ & 81 & 88 & 826 & 995 \\
\hline
\end{tabular}

第二期 鶬料給與基

\begin{tabular}{|c|c|c|c|c|c|}
\hline 生﨎采晋 & &  & エンシレーヂ & 混合飼料 & 合計 \\
\hline \multirow{3}{*}{346} & 重 量 $(\mathrm{kg})$ & 5.00 & 20.00 & 6.60 & \\
\hline & 港 粉 貲 $(\mathrm{kg})$ & 0.584 & 1.520 & 3.678 & 5.78 \\
\hline & 的消化蛋白望 $(\mathrm{g})$ & 81 & 72 & 777 & 930 \\
\hline \multirow{3}{*}{353} & 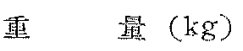 & 4.50 & 24.40 & 7.00 & - \\
\hline & 瀶 粉 侕 $(\mathrm{kg})$ & 0.525 & 1.854 & 3.899 & 6.28 \\
\hline & 可消化蛋混筫 $(\mathrm{g})$ & 72 & 88 & 826 & 986 \\
\hline
\end{tabular}




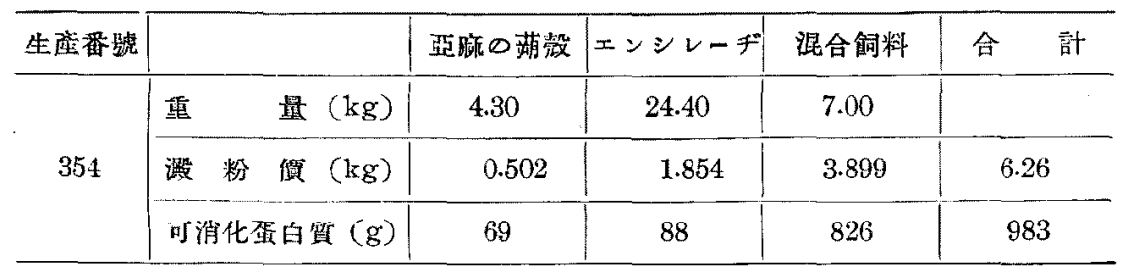

\section{飼 宦 管 理}


11 時, チ後 4 時の3 何で常に同一牧夫に㩁乳させた。

领料水は每日充分に攝取させることに注意した。尚供試牛は相隣接して終


to

生體量は各像借期及び各本試驗期の初日に測定した。

前記の給與飼料は次表の樣にして動物に給與した。

㱸位は $\mathrm{kg}$

\begin{tabular}{|c|c|c|c|c|c|c|c|c|c|c|}
\hline \multirow{3}{*}{ 牝卅番號 } & \multicolumn{2}{|r|}{ 全 } & 試 & \multirow[t]{2}{*}{ 䶨 } & \multicolumn{2}{|l|}{ 期 } & \multicolumn{2}{|c|}{ 第 1 期及籍 3 期 } & \multirow{2}{*}{$\frac{\text { 第 }}{\text { 嗇 }}$} & 2 期 \\
\hline & \multicolumn{2}{|c|}{ 朝 } & 畫 & & \multicolumn{2}{|c|}{ g } & 橎 & 夕 & & 夕 \\
\hline & $\begin{array}{l}\text { 濃厚 } \\
\text { 飼料 }\end{array}$ & 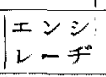 & 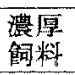 & $\begin{array}{l}\text { エンジ } \\
\text { レーギ }\end{array}$ & $\begin{array}{l}\text { 嶩厚 } \\
\text { 飼料 }\end{array}$ & $\mid \begin{array}{l}x ン シ \\
v ー f ゙\end{array}$ & 程 藮 & 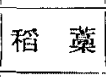 & 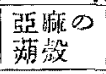 & 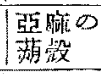 \\
\hline 346 & 2.5 & 9.0 & 1.6 & 5.0 & 2.5 & 6.0 & 2.26 & 2.50 & 2.50 & 2.50 \\
\hline 353 & 2.5 & 10.0 & 2.0 & 7.4 & 2.5 & 7.0 & 1.78 & 2.50 & 2.00 & 2.50 \\
\hline 354 & 2.5 & 10.0 & 2.0 & 7.4 & 2.5 & 7.0 & 1.59 & 2.50 & 1.80 & 2.50 \\
\hline
\end{tabular}

\section{實 驗 結 果}

本試驗は昭和 11 年 1 月 16 日より開始し同年 2 月 29 日に終了した。乳 量, 脂肪量及ざ脂能率に就て其結果を見ると次の樣である。

乳星 (單位 $\mathrm{kg}$ )

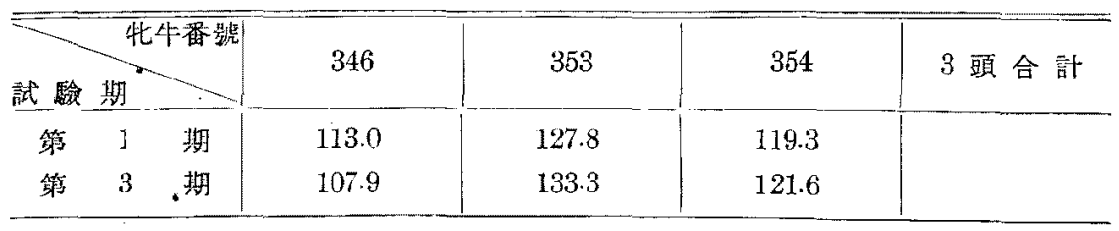




\begin{tabular}{|c|c|c|c|c|c|}
\hline \multirow{2}{*}{\multicolumn{2}{|c|}{ 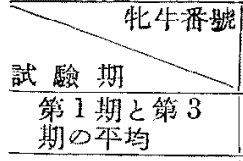 }} & 346 & 353 & 354 & 3 頭合計 \\
\hline & & 110.5 & 130.6 & $120-5$ & 361.6 \\
\hline 第 & 期 & 115.9 & 136.8 & 128.3 & 381.0 \\
\hline 賻 & 減 & +5.4 & +6.2 & +7.8 & +19.4 \\
\hline
\end{tabular}

脂 括盟 (單位 $\mathrm{kg}$ )

\begin{tabular}{|c|c|c|c|c|c|}
\hline 試驗， & 物 & 346 & 353 & 354 & 3 頭の合計 \\
\hline 第 & I 期 & 3.578 & 4.140 & 3.968 & \\
\hline 第 & 3 期 & 3.416 & 4.143 & 3.877 & \\
\hline 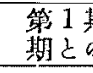 &  & 3.497 & 4.142 & 3.923 & 11.562 \\
\hline 第 & 期 & 3.669 & 4.438 & 4.346 & 12.456 \\
\hline 壇 & 隇 & +0.172 & +0.296 & +0.426 & +0.894 \\
\hline
\end{tabular}

\begin{tabular}{|c|c|c|c|c|}
\hline & & 盺 & & \\
\hline 試驗 & 346 & 353 & 354 & 3 頭の平均 \\
\hline 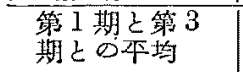 & $3.16 \%$ & $3.17 \%$ & $3.26 \%$ & $3.20 \%$ \\
\hline $\begin{array}{lll}\text { 第 } & 2 & \text { 期 }\end{array}$ & $3.17 \%$ & $3.24 \%$ & $3.39 \%$ & $3.27 \%$ \\
\hline 增 & $+0.01 \%$ & $+0.07 \%$ & $+0.13 \%$ & $0.07 \%$ \\
\hline
\end{tabular}

生體量

\begin{tabular}{|c|c|c|c|c|c|}
\hline \multicolumn{2}{|c|}{ 牡 牛 番 號 } & 346 & 353 & 354 & 備＼cjkstart考 \\
\hline \multirow{2}{*}{$\begin{array}{l}\text { 第 } \\
1 \\
\text { 期 }\end{array}$} & 穆備試羷 開始 & 498 & 592 & 608 & 試 襝 前 \\
\hline & 本試驗開始 & 500 & 608 & 610 & \\
\hline \multirow{2}{*}{$\begin{array}{l}\text { 第 } \\
2 \\
\text { 期 }\end{array}$} & 㘈 備試驗開始' & 506 & 589 & 602 & 第 1 期成縝 \\
\hline & 本試彩關始 & 492 & 610 & 608 & \\
\hline \multirow{3}{*}{$\begin{array}{c}\text { 第 } \\
3 \\
\text { 期 }\end{array}$} & 瑔備試驗開始 & 508 & 614 & 614 & 第 2 期成続 \\
\hline & 本試驗開始 & 504 & 584 & 608 & \\
\hline & 本試憈 終了 & 514 & 616 & 618 & 第 3 期成綪 \\
\hline
\end{tabular}




\section{考察}

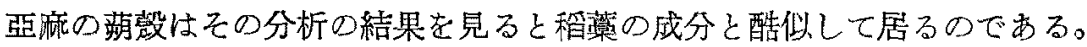

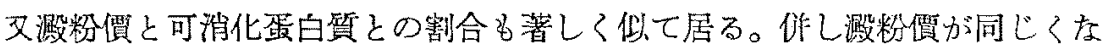

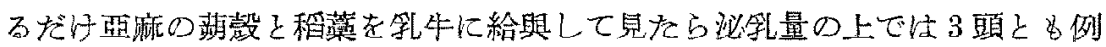


2 期の方が，量は少いが，例外なく何れも貌乳量を增して居る。3嗢の平均は


りる泌乳上に好影響があると考へられる。又脂肪量に就て見るも同様 3 頭共

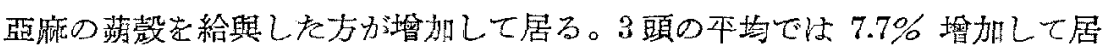

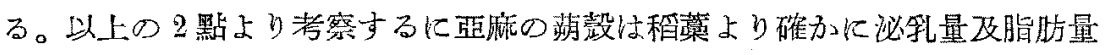
を增加するものであると言へる。次に脂肪率に就て考へるに 3 頭共僅かなが

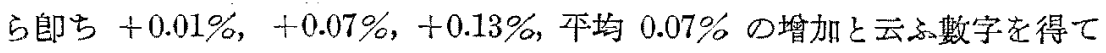
居る。0.07\% の增师とは本試驗に於ては全々誤差の範圍を出度い。然し何れ

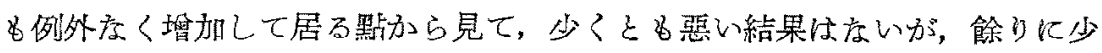
いので，脂肪率には影響はない見てよい。


案を低下し索いと云へる。

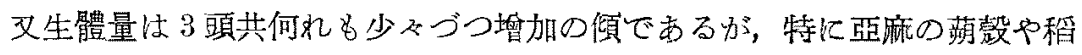

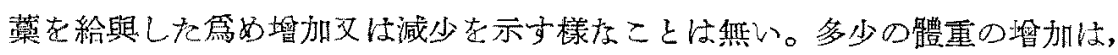
恐らく動物が完熟して居ない篇であつて，次第に順罣に生體量か增加して居

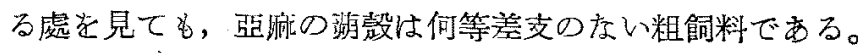

綜括

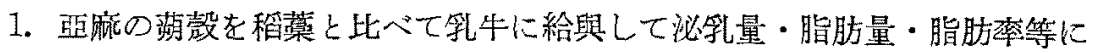
就て試驗を行つた。



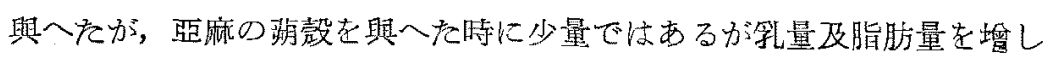
た。又脂肪率も減少与る滕度事が加つた。

3，上述の試驗に於て特に生體量の增減する樣店傾は認められなかつた。 